\title{
Editorial
}

\section{In Favour of a Proactive Insurance Approach to Climate Change}

\author{
Walter R. Stahel \\ The Geneva Association, 53 Route de Malagnou, Geneva CH-1208, Switzerland. \\ E-mail: secretariat@genevaassocation.org
}

The Geneva Papers (2009) 34, 319-322. doi:10.1057/gpp.2009.17

\section{Science and climate change}

The Geneva Papers is a highly respected refereed scientific journal, submitted to the strict rules governing this kind of publication. One of these rules is references - every paper is supposed to have references to show its integration into the scientific body of knowledge of the subject treated.

This poses a problem with the subject of this Special Issue - Climate Change and Insurance. There is no equivalent to the foundation of economics, such as Das Kapital by Karl Marx, or Schumpeter's books, for climate change. Climate change as a subject for historians goes back to mediaeval times, and the first known publications and pictures were European. Climate change as a scientific subject, mostly limited to meteorological observations, goes back some centuries; the main global data available is from the ships of the Royal Navy, which recorded the seawater temperature every 6 hours, the date and the geographic location. Pictures of artists, such as Brueghel, are another source of information, enabling us to see that winters in The Netherlands, for instance, were a freezing affair.

This does not mean that other regions with a long scientific tradition, such as China, India or Japan had not studied climate and weather changes; non-Asians experts and search engines simply have no easy access to the relevant language publications.

For Renaissance man, climate was a physical phenomenon where man's task was to decipher the mechanisms and rules. Only in 1719, the French politician Montesquieu launched an appeal to the scientists of all nations to realise a project of the physical history of the world, encompassing natural history, geography, geology and climate. The objective was to determine changes due to man's influence that have given a new face to Earth. "To understand climate, we need a continuous and well documented history of winds, rains, asteroids, of warm and cold temperatures, each year, each season, each day", wrote Duhamel de Monceau (1743) in his Observations météorologiques. Several observation networks had been established in order to detect variations between regions and countries and deduct the underlying scientific explications. Exceptional years were not interpreted as a sign of deregulation but as an indication of insufficient knowledge of the underlying laws still to be discovered.

In 1778, Buffon published Les Epoques de la nature in which he suggested that the development of human settlements, the drainage of moors and deforestation were at 
the beginning of negative conditions that influenced the climate. "The disappearance of a single forest in a country is sufficient to change the temperature. For trees attract the cold, they diminish the heat of the sun and produce vapour that creates clouds which lead to rain". 1

But, until the end of the 18th century, the idea of man-made climate change was mostly incompatible with the religious notion of creation: God's work was perfect and not to be interfered with by mankind.

In 1824, the French physicist Fourier first developed the idea that all the temperature effects on land were due to interactions between the atmosphere and the oceans. The first to link the global greenhouse effect with the carbon cycle, the Swedish scientist, Svante Arrhenius, foresaw a radiant future for humanity through the resulting changes. In The Evolution of the Worlds (1910), he wrote: "the increase of carbon gas in the atmosphere allows us to hope for periods of warmer climatic conditions, especially in the cold regions of our planet. These periods will allow the land to produce considerable better harvest than today, which will be a godsend for the populations that are increasing faster than ever". And he was right: the European Commission forecasts increases of over 50 per cent in the agricultural yields of Scandinavia over the coming years.

Scientific observations have been highlighted by the tales of courageous explorers racing to be the first on the North and South Poles, which have fascinated large parts of the population of the Northern hemisphere. In fact, climate and the impact of climate change on people has always been a regional issue. Today, rises in the average temperature cause fears for severe droughts in Africa and the southern hemisphere, but rejoice the prospects for economic development in Siberia and Scandinavia.

The first attempt to describe climate change on a global level goes back to the foundation of the Intergovernmental Panel for Climate Change of the United Nations (UN IPCC). The complexity of the task rapidly led to attempts to build a model of global climate change; but each model is limited to a number of criteria. Present models, for instance, still exclude the solar cycles and their influence on climate change. It is, therefore, unrealistic to expect a general agreement on the validity of the results from the models among scientific experts. In addition, the reputation of the modelling business itself may have suffered a severe blow through the subprime crises leading to the credit crises and an economic world crisis that no model had even anticipated.

To this day, the climate change discussion remains Eurocentric, with dissident opinions in the Anglo-Saxon world. The views of Asia, Australia, Africa and South America are not on the forefront or simply unheard. This Eurocentrism, which includes North America, is also mirrored in the present Special Issue of The Geneva Paper on climate change and insurance.

\section{Insurance and climate change}

The insurance industry has been feeling the impacts of climatic changes for many years in its loss experience, but has also experienced the great volatility of the data.

\footnotetext{
${ }^{1}$ See the article 'Buffon et l'effet de serre' by René Favier ; in: L'histoire no. 340, March 2009, pp. 28-29.
} 
The potential effects of anthropogenic climate change on insured property losses were anticipated as early as 1973, when Munich Re stated in a brochure on Flood/Inundation:

Investigations into the overall trend of claims experience are indispensable, and here climatic variations become most significant. Such investigations involve a study of thermodynamic processes such as, for example, the rising temperature of the earth's atmosphere (as a result of which glaciers and the polar caps recede ...). ... We wish to enlarge on this complex of problems in greater detail, especially as ... its conceivable impact on the long-range risk trend has hardly been examined to date. ${ }^{2}$

In 1979, the Fire and Marine Insurance Rating Association of Japan released the publication Research of Disaster, vol. 10, which carries an article named "Future of the environmental carrying capacity, from the climate change perspective" by Masatoshi Yoshino. This article sounds the alarm about the possibility of future climate change as follows:

There is a prediction that, in the 21 st century, we will have remarkable high temperatures that have not been experienced in past 1,000 years.

Only in the early 21 st century, the first attempt was made to estimate the impact of climate change on the world economy. In 2006, Sir Nicolas Stern published his report. But, Sir Nicolas had to introduce limitations into his calculations, such as a zero depreciation rate, which makes his analysis vulnerable to criticism by fellow economists.

In the past, the insurance industry has shown a reactive attitude to climate change, following a largely event-driven and policy-driven approach that has neglected key parameters of insurance that need to be put into better evidence:

- the insurance industry is part of the private sector,

- the insurance industry's role is to assess and manage risk in order to reduce other people's volatility,

- risks have to be insurable and have to be priced in a competitive way.

In order to put insurance's possible contributions to the mitigation and adaptation of climate change into the right perspective, the insurance industry will need to better explain its role within the economy in a proactive approach, which itself must be based on a generally acceptable vision of the future. A world low-carbon economy is the accepted vision for this century today.

This wider perspective is put into evidence in the report "The Insurance Industry and Climate Change, Contribution to the Global Debate", which will be published by The Geneva Association in July 2009.

\footnotetext{
${ }^{2}$ Munich Re (1973) Flood/Inundation, Munich, August 1973.
} 


\section{The special issue of The Geneva Papers on climate change and insurance}

What are the lessons of these issues for this Special Issue of The Geneva Papers? Insurance and climate change are not congruent subjects, most insurance activities being focused on industrialised countries, whereas developing countries may be harder hit by the impacts of climate changes.

Most analytical articles are limited to a geographic region, and most scientific articles will have the aspect of an exploratory nature. Readers should thus not be too demanding with regard to a global view, or references from a broad range of sources.

The first paper gives a global review of insurance industry responses to climate change; it is written by a leading scientist who has been among the first to research this field.

The second paper looks into adaptation to climate change and is written by experts in catastrophe modelling. Supporting adaption measures in industrialised countries makes sense as most of the insured assets are in these regions.

The following paper highlights possible contributions of insurance to developing countries. As many of the potential customers cannot pay any premiums, the solutions are linked with the idea of public-private partnerships. The paper is written by an authors' collective, which includes policy-makers and insurance experts.

The paper on weather index insurance and climate change details the issue of insuring agricultural production losses in developing countries which are novel in the sense that the insurer will pay when an insured event has occurred, independently of the loss incurred. The author is an economist working for an organisation involved in micro-lending activities.

The final paper looks into the methods to estimate the impact of non-catastrophic weather upon commercial enterprises. The author is an economist doing research on implementation and pricing issues of weather derivatives. 